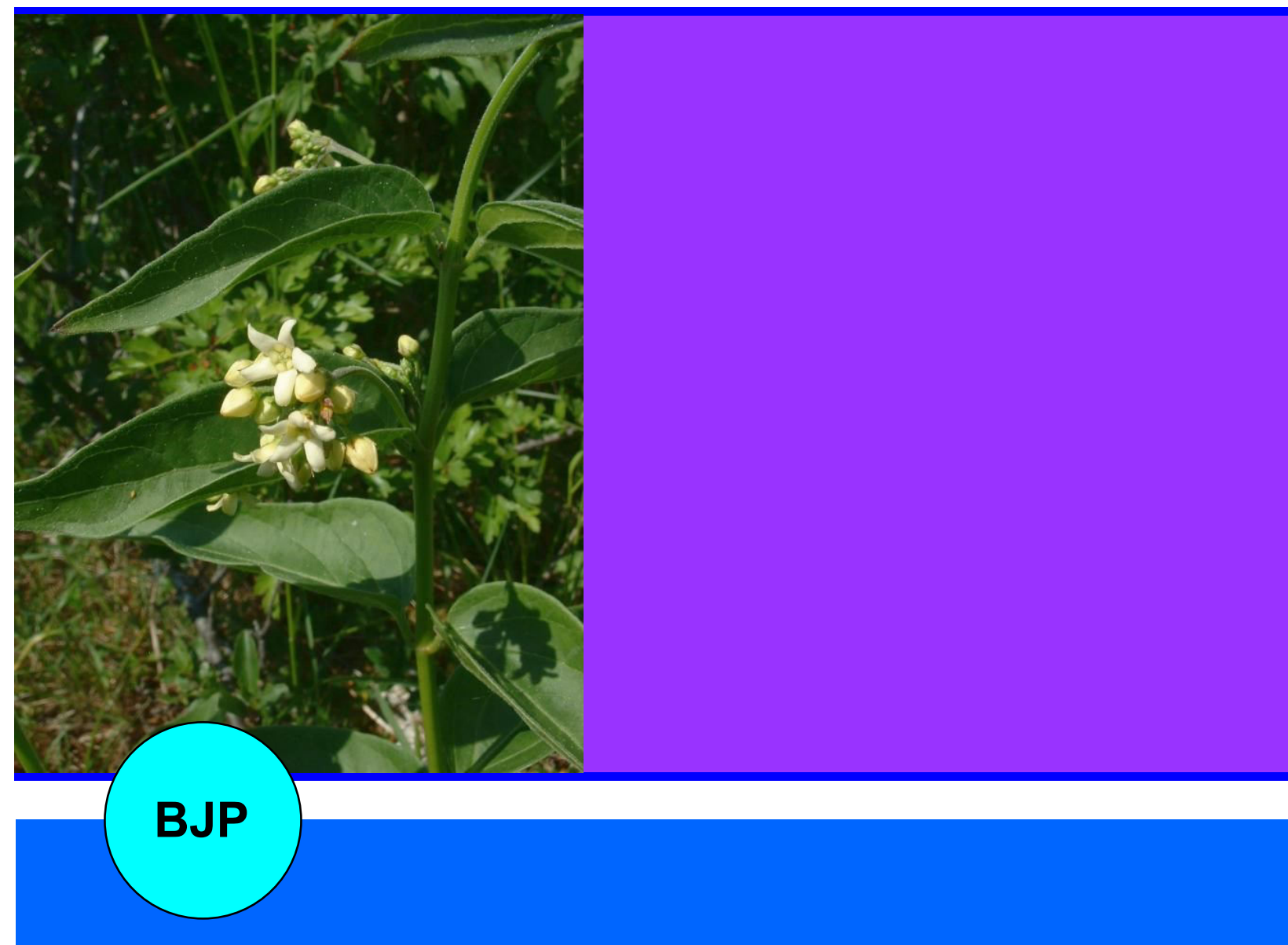

Bangladesh Journal of Pharmacology

Research Article

Antidiarrheal and antispasmodic activities of Vincetoxicum stocksii are mediated through calcium channel blockade 


\title{
Antidiarrheal and antispasmodic activities of Vincetoxicum stocksii are mediated through calcium channel blockade
}

\author{
Abdul Jabbar Shah',2, Mudassar A. Zaidi3, Hassan Sajjad', Hamidullah'1 and \\ Anwarul-Hassan Gilani \\ ${ }^{1}$ Natural Product Division; Department of Biological and Biomedical Sciences Aga Khan University Medical College, \\ Karachi, Pakistan; ${ }^{2}$ Department of Pharmacy, COMSATS, Institute of Information Technology, University Road \\ Abbottabad 220 60l, Pakistan; ${ }^{3}$ Department of Botany, Baluchistan University, Quetta, Pakistan.
}

\begin{tabular}{|c|c|}
\hline \multicolumn{2}{|l|}{ Article Info } \\
\hline Received: & 17 August 2011 \\
\hline Accepted: & 18 August 2011 \\
\hline Available Online: & 21 August 2011 \\
\hline \multicolumn{2}{|c|}{ DOI: 10.3329/bjp.v6i1.8403 } \\
\hline \multicolumn{2}{|c|}{$\begin{array}{l}\text { Cite this article: } \\
\text { Shah AJ, Zaidi MA, Sajjad H, Ha- } \\
\text { midullah, Gilani AH. Antidiarrheal } \\
\text { and antispasmodic activities of Vince- } \\
\text { toxicum stocksii are mediated through } \\
\text { calcium channel blockade. Bangla- } \\
\text { desh J Pharmacol. 2011; } 6: 46-50 \text {. }\end{array}$} \\
\hline
\end{tabular}

\begin{abstract}
This study was carried out to explore the mechanism underlying antidiarrheal and antispasmodic activities of Vincetoxicum stocksii. The crude extract of $V$. stocksii provided $12-24 \%$ protection from castor oil-induced diarrhea at the dose of $300-1,000 \mathrm{mg} / \mathrm{kg}$, similar to loperamide. In isolated rabbit jejunum preparations, $V$. stocksii caused inhibition of the spontaneous and high $\mathrm{K}^{+}(80 \mathrm{mM})$-induced contractions, with respective $\mathrm{EC}_{50}$ values of 2.5 (1.7-3.9) and $1.0 \mathrm{mg} / \mathrm{mL}(0.6-1.4)$, similar to that caused by verapamil, suggesting the calcium channel blocking effect. Loperamide caused inhibition of spontaneous and high $\mathrm{K}^{+}$-induced contraction, with respective $\mathrm{EC}_{50}$ values of $8.6(6.3-10.1)$ and $9.1 \mu \mathrm{M}(7.3-12.8)$. The calcium channel blocking activity was further confirmed when pretreatment of the tissues with $V$. stocksii (1-3 $\mathrm{mg} / \mathrm{mL}$ ) caused a rightward displacement of the $\mathrm{Ca}^{++}$concentrations response curves, similar to that produced by verapamil; constructed in $\mathrm{Ca}^{++}$ free medium. These data indicate that the crude extract of $V$. stocksii contains calcium channel blocking constituents that may possibly explain its medicinal use in hyperactive states of gut, such as, diarrhea and spasms.
\end{abstract}

\section{Introduction}

Vincetoxicum stcoksii Ali and Khatoon belongs to the Asclepiadaceae (milkweed) family and is a group of perennial climbing leafy vines (Zaidi and Crow, 2005). Vincetoxicum is distributed throughout the tropical American continent, Europe and Asia. Phytochemistry of the plant revealed the presence of some glycosides and alkaloids (Zaidi and Crow, 2005). The plant is not well studied biologically or pharmacologically, except for antibacterial and antifungal activities.

This study describes the antidiarrheal and antispasmodic activities of the crude extract of $V$. stocksii with possible mode of action explored.

\section{Materials and Methods \\ Plant materials}

Aerial parts of $V$. stocksii (800 g) were obtained from Quetta Baluchistan and authenticated by Prof. Musaddar A Zaidi. A voucher specimen (VT-LF-09-02-57) was deposited at the herbarium located at the Department of Biological and Biomedical Sciences, Aga Khan University, Karachi, Pakistan.

\section{Preparation of crude extract}

Preparation of the crude extract was carried out as described previously (Gilani et al., 2005). The powdered material was soaked in $70 \%$ aqueous-methanol for three 
days with occasional shaking. It was filtered through a muslin cloth and then through a whatmann qualitative grade 1 filter paper. This procedure was repeated thrice and the combined filtrate was evaporated on a rotary evaporator at $37^{\circ} \mathrm{C}$ under reduced pressure $(-760 \mathrm{~mm}$ $\mathrm{Hg}$ ) to a thick, semi-solid mass of brown color, i.e. the crude extract, yielding approximately $41 \%(\mathrm{w} / \mathrm{w})$. The crude extract was solubilized in normal saline for use in the in vivo and in vitro experiments. $V$. stocksii crude extract was screened for the presence of saponins, flavonoids, flavanols, flavones, tannins, phenols, coumarins, sterols, terpenes, alkaloids and anthraquinones by using methods described by Wall et al. (1952).

\section{Chemicals}

The following reference chemicals were obtained from the sources specified: Loperamide hydrochloride, acetylcholine chloride, verapamil hydrochloride, potassium chloride (Sigma Chemical Company, St. Louis, MO, U.S.A.) and castor oil (Karachi Chemical Industries, Karachi, Pakistan). All chemicals used were of the highest purity grade available. Stock solutions of all the chemicals were made in distilled water and the dilutions were made fresh in normal saline on the day of the experiment.

Experiments performed complied with the rulings of the Institute of Laboratory Animal Resources, Commission on Life Sciences, National Research Council (National Research Council, 1996) and were approved by the Ethical Committee of Aga Khan University Karachi, Pakistan. BALB-c albino mice (20-25 g) and local rabbits $(1.5-2 \mathrm{~kg}$ ) of either sex used in the study were bred and housed in the animal house of Aga Khan University in a controlled environment $\left(23-25^{\circ} \mathrm{C}\right)$. Animals were given tap water ad libitum and a standard diet.

\section{Antidiarrheal protocol}

The in vivo antidiarrheal activity of the extract was investigated following the methods previously described (Awouters et al., 1978; Jebunnessa et al., 2009; Shah et al., 2010). In the present study BALB-c albino mice were fasted for 18 hours. The animals were divided in five groups, housed in five steel cages with five mice in each and the bottom of each cage was covered with a blotting sheet. The first group received saline $(10 \mathrm{~mL} /$ $\mathrm{kg}$, p.o.) as the vehicle control and so acted as the negative control. The second group received castor oil. Groups third and fourth received two doses (300 and $1,000 \mathrm{mg} / \mathrm{kg}$ ) of the crude extract of $V$. stocksii, which were selected on a trial basis and administered orally by an intra-gastric feeding needle. Groups fifth received loperamide $(10 \mathrm{mg} / \mathrm{kg})$ orally, and served as positive control. One hour after treatment each animal received $10 \mathrm{~mL} / \mathrm{kg}$ of castor oil orally and was then observed for defecation. Up to 4 hours after the castor oil challenge, the presence of diarrheal droppings was noted on blotting sheets in the individual cages. Percent protection against the castor oil-induced diarrhea was calculated based on the number of dry feces in each cage in comparison to the wet.

The isolated tissue experiments were carried out as described previously (Shah et al., 2010). The animals had free access to water but were fasted for 24 hours before the experiment. The animals were sacrificed by cervical dislocation, the abdomen was cut open and the jejunal portion isolated out. Preparations $2 \mathrm{~cm}$ long were mounted in $10 \mathrm{~mL}$ tissue baths containing normal Tyrode's solution maintained at $37^{\circ} \mathrm{C}$ and aerated with a mixture of $5 \%$ carbon dioxide in oxygen (carbogen). The composition of Tyrode's solution, in mM, was: $\mathrm{KCl}$ 2.7, $\mathrm{NaCl} 136.9, \mathrm{MgCl}_{2}$ 1.1, $\mathrm{NaHCO}_{3}$ 11.9, $\mathrm{NaH}_{2} \mathrm{PO}_{4} 0.4$, Glucose 5.6 and $\mathrm{CaCl}_{2} 1.8$ (pH 7.4). A preload of $1 \mathrm{~g}$ was applied and the tissues kept undisturbed for an equilibrium period of $30 \mathrm{~min}$ after which control responses to a sub-maximal dose of acetylcholine $(0.3 \mu \mathrm{M})$ were obtained and the tissue presumed stable only after the reproducibility of the said responses.

Under these experimental conditions, rabbit jejunum exhibits spontaneous rhythmic contractions, allowing the testing of relaxant (spasmolytic) activity directly without the use of an agonist (Gilani et al., 1994).

\section{Calcium channel blocking activity}

To assess whether the spasmolytic activity of the test substances was mediated through calcium channel blockade, high concentration of $\mathrm{K}^{+}(80 \mathrm{mM})$, as $\mathrm{K}^{+}$, was used to depolarize the preparations (Farre et al., 1991). $\mathrm{K}^{+}(80 \mathrm{mM})$ was added to the tissue bath, which produced a sustained contraction. Plant extract and standards were then added in a cumulative fashion to obtain concentration-dependent inhibitory responses (van-Rossum, 1963). The relaxation of intestinal preparations, precontracted with high $\mathrm{K}^{+}$, was expressed as percent of the control precontraction.

To confirm the calcium antagonist activity of test substances, the tissue was allowed to stabilize in normal Tyrode's solution, which was then replaced with $\mathrm{Ca}^{++}$-free Tyrode's solution containing EDTA $(0.1 \mathrm{mM})$ for $30 \mathrm{~min}$ in order to remove $\mathrm{Ca}^{++}$from the tissues. This solution was further replaced with $\mathrm{K}^{+}$-rich and $\mathrm{Ca}^{++}$-free Tyrode's solution, having the following composition: $\mathrm{KCl} 50, \mathrm{NaCl} 91.0, \mathrm{MgCl}_{2}$ 1.1, $\mathrm{NaHCO}_{3}$ 11.9, $\mathrm{NaH}_{2} \mathrm{PO}_{4}$ 0.4, glucose 5.6 and EDTA $0.1 \mathrm{mM}$, with $\mathrm{pH}$ of 7.4. Following an incubation period of $30 \mathrm{~min}$, control concentration-response curves of $\mathrm{Ca}^{++}$were obtained. When the control concentration-response curves of $\mathrm{Ca}^{++}$were found super-imposable (usually after two cycles), the tissue was pretreated with the plant extract for $60 \mathrm{~min}$ to test the possible calcium channel blocking effect. The concentration-response curves of $\mathrm{Ca}^{++}$were reconstructed in the presence of different concentrations of the test material. 


\section{Statistics}

All the data expressed are mean \pm standard error of the mean (SEM), and the median effective concentrations (EC50 values) are given with $95 \%$ confidence intervals (CI). The statistical parameter applied is the Student's ttest with $p<0.05$ noted as significantly different (GraphPad Prism).

\section{Results and Discussion}

The crude extract of $V$. stocksii was tested for its antidiarrheal activity. In the castor oil-induced diarrhea in mice, the crude extract of $V$. stocksii, like loperamide, a standard antidiarrheal agent (Reynolds et al., 1984), inhibited significantly $(p<0.05)$ the frequency of defecation as well as wetting of feces when compared with the untreated group (i.e. mice receiving neither extract, nor loperamide, but castor oil only). Crude extract of $V$. stocksii and loperamide reduced greatly the wetness of the fecal droppings and provided around $12.7 \pm 3.1$ to $24.4 \pm 4.5$ and $94.8 \pm 1.4 \%$ protection, respectively (Table I). The induction of diarrhea by castor oil results from the action of recinoleic acid formed in the hydrolysis of the oil (Iwao and Terada, 1962), which produces changes in the transport of water and electrolytes and results in a hypersecretory response and generation of giant contraction of the intestine (Croci et al., 1997).

Thus, a potential antidiarrheal agent may exhibit its antidiarrheal effect by inhibiting either gut motility and/or electrolyte out flux (Croci et al., 1997). The protective effect of the crude extract of $V$. stocksii against the castor oil-induced diarrhea in mice, similar to loperamide, suggests that it has either an inhibitory effect on contraction or on electrolyte out flux. To see its possible inhibitory effect on gut motility, the $V$. stocksii was further studied in the in vitro experiments.

When tested in isolated rabbit jejunum preparations, cumulative addition of plant extract, verapamil and loperamide caused concentration-dependent inhibition of the spontaneous contractions, with respective $\mathrm{EC}_{50}$ values of $2.5 \mathrm{mg} / \mathrm{mL}$ (1.7-3.9), $0.2 \mu \mathrm{M}(0.1-0.3)$ and 8.6 $\mu \mathrm{M}$ (6.3-10.1) (Figure 1), thus showing smooth muscle relaxant (spasmolytic) activity.

Our previous observation revealed that the spasmolytic constituents present in the extracts of different medicinal plants mediate their effect usually through a calcium channel blocking effect (Gilani et al., 2005; Shah et al., 2010). To see whether the spasmolytic effect of the plant extract observed in this study is also mediated through a calcium channel blocking like effect, a high concentration of $\mathrm{K}^{+}(80 \mathrm{mM})$ was produced sustained contractions. The crude extract was then added in a cumulative fashion, where it caused a concentration-dependent relaxation of the induced contractions with an EC-50 value of $1.0 \mathrm{mg} / \mathrm{mL}(0.6-1.4)$, as shown in Figure 1, suggests that the spasmolytic effect is possibly mediated through a calcium channel blocking-like effect. Similarly, verapamil and loperamide also caused a concentration-related inhibitory effects against high $\mathrm{K}^{+}$ induced contractions with respective $\mathrm{EC}_{-50}$ values of $0.03 \mu \mathrm{M}(0.02-0.04)$ and $9.1 \mu \mathrm{M}$ (7.3-12.8) (Figure 1). Crude extract of $V$. stocksii was more potent against $\mathrm{K}^{+}$ induced contractions, similar to verapamil, which suggests that plant extract mediates its spasmolytic effect possibly through calcium channel blockade.

The contractions induced by high $\mathrm{K}^{+}(>30 \mathrm{mM})$ are dependent on the entry of $\mathrm{Ca}^{++}$into the cells through voltage dependent channels (Bolton, 1979) and a substance which can inhibit high $\mathrm{K}^{+}$-induced contractions is therefore, possibly considered to be a calcium channel blocker (Godfraind et al., 1986). Thus, the inhibition of high $\mathrm{K}^{+}$-induced contractions of rabbit jejunum by Vs.Cr may reflect the restricted $\mathrm{Ca}^{++}$entry via voltagedependent channels.

The contractions induced by high $\mathrm{K}^{+} 30<$ dependent on the entry of $\mathrm{Ca}^{++}$nto the cells through voltage dependent channels (Bolton, 1979) and a substance which can inhibit high $\mathrm{K}^{+}$-induced contractions is therefore, possibly considered to be a calcium channel blocker (Godfraind et al., 1986). Thus, the inhibition of high $\mathrm{K}^{+}$-induced contractions of rabbit jejunum by

Table I

Effect of the crude extract of Vincetoxicum stocksii on castor oil-induced diarrhea in mice

\begin{tabular}{|lcc|rr|}
\hline Group & Dose & $\begin{array}{c}\text { Total number of } \\
\text { feces in } 4 \text { hours }\end{array}$ & $\begin{array}{c}\text { Total number of wet } \\
\text { feces in } 4 \text { hours }\end{array}$ & Protection (\%) \\
\hline Control & $10 \mathrm{~mL} / \mathrm{kg}$ & $12.7 \pm 0.9$ & $0.4 \pm 0.2$ & $99.0 \pm 0.9$ \\
Castor oil & $10 \mathrm{~mL} / \mathrm{kg}$ & $13.8 \pm 0.2$ & $13.0 \pm 0.8$ & $1.0 \pm 0.2$ \\
Castor oil + extract & $10 \mathrm{~mL} / \mathrm{kg}+300 \mathrm{mg} / \mathrm{kg}$ & $13.6 \pm 1.5$ & $87.3 \pm 3.1$ & $12.7 \pm 3.1 \mathrm{a}$ \\
Castor oil + extract & $10 \mathrm{~mL} / \mathrm{kg}+1,000 \mathrm{mg} / \mathrm{kg}$ & $6.8 \pm 0.9$ & $75.6 \pm 4.5$ & $24.4 \pm 4.5^{\mathrm{b}}$ \\
Castor oil + loperamide & $10 \mathrm{mg} / \mathrm{kg}+10 \mathrm{mg} / \mathrm{kg}$ & $8.8 \pm 1.2$ & $0.4 \pm 0.3$ & $94.8 \pm 1.4$ \\
Results are mean \pm SEM; $\mathrm{n}=5$; aSignificantly different from control, $\mathrm{p}<0.05$; Significantly different from control, $\mathrm{p}<0.01$ & \\
\hline
\end{tabular}



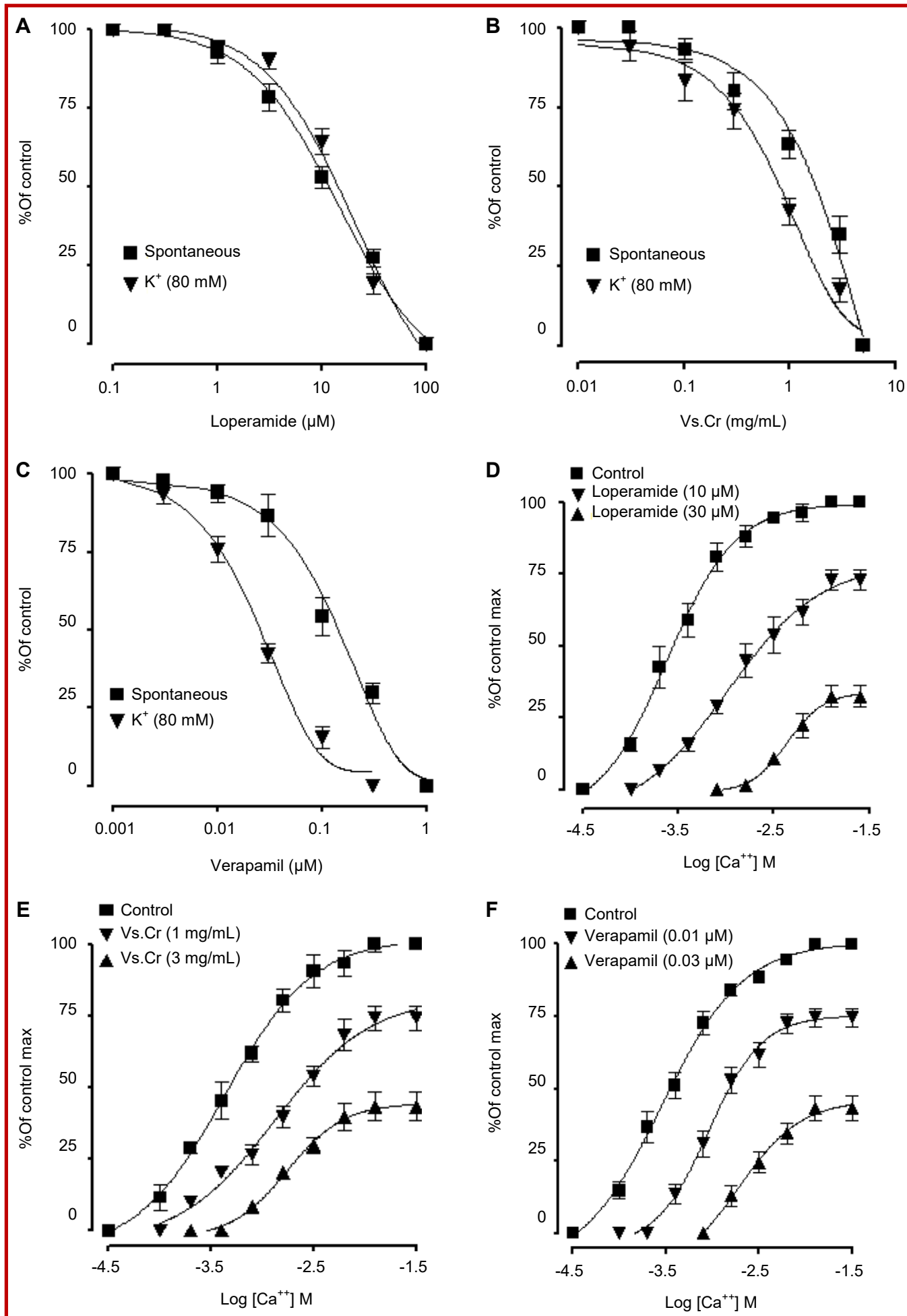

Figure 1: Concentration-response curves of (A) the crude extract of Vincetoxicum stocksii (Vs.Cr), (B) verapamil and (C) loperamide on spontaneous and $\mathrm{K}^{+}(80 \mathrm{mM})$-induced contractions in isolated rabbit jejunum preparations. Figures $\mathrm{D}, \mathrm{E}$ and $\mathrm{F}$, show respectively, the effect of Vs.Cr verapamil and loperamide on the $\mathrm{Ca}^{++}$concentration-response curves in isolated rabbit jejunum preparations. Values shown are mean $+\mathrm{SEM} ; \mathrm{n}=6-9$ 
extract may reflect the restricted $\mathrm{Ca}^{++}$entry via voltagedependent channels.

This hypothesis was further strengthened when pretreatment of the tissues with crude extract of $V$. stocksii (1-3 mg/mL) caused a rightward shift in the $\mathrm{Ca}^{++} \mathrm{CRCs}$ (Figure 1D), similar to verapamil (Figure 1). Pretreatment of the tissues with loperamide also caused a rightward shift in the $\mathrm{Ca}^{++} \mathrm{CRCs}$ (Figure 1), which is in accordance to its known calcium channel blocking effect at antidiarrheal doses (Reynolds et al., 1984). These data indicate that crude extract of $V$. stocksii possesses a calcium channel blocking effect similar to verapamil, which provides pharmacological basis to its antidiarrheal and antispasmodic effects, as calcium channel blockers are considered useful in diarrhea and gut spasms (Pasricha, 2006).

Preliminary phytochemical analysis of the plant extract revealed the presence of tannins and glycosides while other groups were found absent. The plant derived tannins are known to possess calcium channel blocking and antidiarrheal activities (Zhu et al., 1997) and the presence of tannins in this plant may explain the antidiarrheal and the calcium channel blocking activities of the plant.

\section{Conclusion}

Crude extract of $V$. stocksii possesses antidiarrheal and antispasmodic effects mediated possibly through calcium channel blockade.

\section{Acknowledgement}

This study was supported in part by the Pakistan Science Foundation.

\section{References}

Awouters F, Niemegeers CJE, Lenaerts FM, Janssen PAJ. Delay of castor oil diarrhea in rats: A new way to evaluate inhibitors of prostaglandin biosynthesis. J Pharm Pharmacol. 1978; 30: 41-45.

Bolton TB. Mechanism of action of transmitters and other substances on smooth muscles. Physiol Rev. 1979; 59: 606718 .
Pasricha PJ. Agents affecting gastrointestinal water flux and motility; emesis and antiemetics; bile acids and pancreatic enzymes. In: Brunton LL, Lazo JS, Parker KL (Eds.), Goodman and Gillman's: The Pharmacological Basis of Therapeutics. McGraw Hill, New York, 2006, pp 983-1008.

Croci T, Landi M, Edmonds-Alt X, Le Fur G, Maffrand JP, Manara I. Role of tachykinins in castor oil induced diarrhea in rats. Br J Pharmacol. 1997; 121: 375-80.

Farre AJ, Columbo M, Fort M, Gutierrez B. Differential effects of various $\mathrm{Ca}^{++}$antagonists. Gen Pharmacol. 1991; 22: 177-81.

Gilani AH, Shaheen F, Saeed SA. Cardiovascular actions of Daucus carota. Arch Pharmacal Res. 1994; 17: 150-53.

Gilani AH, Shah AJ, Ghayur MN, Kashif M. Pharmacological basis for the use of turmeric in gastrointestinal and respiratory disorders. Life Sci. 2005; 76: 3089-105.

Godfraind T, Miller R, Wibo M. Calcium antagonism and calcium entry blockade. Pharmacol Rev. 1986; 38: 321-416.

Iwao I, Terada Y. On the mechanism of diarrhea due to castor oil. Jpn J Pharmacol. 1962; 12: 137-45.

Jebunnessa, Uddin SB, Mahbub-Uz-Zaman M, Akatr R, Ahmed NU. Antidiarrheal activity of ethanolic bark extract of Mitragyna diversifolia. Bangl J Pharmacol. 2009; 4: 144-46.

National Research Council. Guide for the care and use of laboratory animals. National Academies Press: Washington DC, 2010. pp 161-175.

Reynolds IJ, Gould RJ, Snyder SH. Loperamide blockade of calcium channel as mechanism for antidiarrheal effects. J Exp Pharmacol Ther. 1984; 231: 628-32.

Shah AJ, Bhulani NN, Khan SH, Rehman N, Gilani AH. Calcium channel blocking activity of Mentha longifolia L. explains its medicinal use in diarrhea and gut spasm. Phytother Res. 2010; 24: 1392-97.

van-Rossum JM. Cumulative dose-response curves. II. Techniques for the making of dose-response curves in isolated organs and the evaluation of drug parameters. Arch Int Pharmacodyn. 1963; 143: 299-330.

Wall ME, Eddy CR, McClenna ML, Klump ME. Detection and estimation of steroid and sapogenins in plant tissue. Anal Chem. 1952; 24: 1337-42.

Zhu M, Phillipson JD, Greengrass PM, Bowery NE, Cai Y. Plant polyphenols: Biologically active compounds or nonselective binders to proteins? Phytochemistry 1997; 44: 44147.

Zaidi MA, Crow SA Jr. Biologically active traditional medicinal herbs from Balochistan, Pakistan. J Ethnopharmacol. 2005; 96: 331-34. 